\title{
KARAKTERISASI SEBARAN BINOMIAL NEGATIF
}

\author{
DEBY HANDAYANI \\ Program Studi Magister Matematika, \\ Fakultas Matematika dan Ilmu Pengetahuan Alam, Universitas Andalas, \\ Kampus UNAND Limau Manis Padang, Indonesia, \\ email : deby.handayani@ymail.com
}

\begin{abstract}
Abstrak. Sebaran Binomial Negatif adalah salah satu peubah acak disktret yang terbentuk dari percobaan Bernoulli. Pada paper ini akan ditentukan karakterisasi dari sebaran Binomial Negatif. Karakterisasi tersebut terdiri dari fungsi kepadatan peluang, nilai harapan, variansi, skewness, kurtosis, fungsi pembangkit momen dan fungsi karakteristik.
\end{abstract}

Kata Kunci: Sebaran binomial negatif, nilai harapan, variansi, skewness, kurtosis, fungsi pembangkit momen, fungsi karakteristik

\section{Pendahuluan}

Distribusi Binomial Negatif merupakan distribusi yang memiliki banyak cara dalam penurunannya, salah satunya adalah sebagai salah satu percobaan Bernoulli yang dibutuhkan sampai terjadi $k$ buah sukses, dengan setiap pengulangannya saling bebas dimana probalitasnya gagal yaitu $1-p$ dan probabilitas sukses $p$.

Jika peubah acak $X$ menyatakan jumlah percobaan yang dibutuhkan sampai terjadi $k$ sukses, maka distribusi probabilitas peubah acak $X$ disebut berdistribusi Binomial Negatif dengan fungsi probabilitas sebagai berikut

$$
P(X=x)=\left(\begin{array}{c}
x-1 \\
r-1
\end{array}\right) p^{r}(1-p)^{x-r},
$$

dimana $x=r, r+1, r+2, \cdots$ dan $0 \leq p \leq 1$.

Distribusi probabilitas dari peubah acak $X$ dapat dinotasikan menjadi bentuk lain, dengan menggunakan tranformasi $Y=X-r$, dimana $Y$ menyatakan jumlah kegagalan sebelum terjadi $k$ sukses. Distribusi probabilitas dari peubah acak $Y$ adalah

$$
P(Y=y)=\left(\begin{array}{c}
r+y-1 \\
y
\end{array}\right) p^{r}(1-p)^{y}
$$

dimana $y=0,1,2, \cdots$ dan $0 \leq p \leq 1$. Distribusi Binomial Negatif dapat juga didefinisikan dengan menggunakan fungsi Gamma sebagai pengganti kombinasi $\left(\begin{array}{c}r+y-1 \\ y\end{array}\right)$ yaitu

$$
\left(\begin{array}{c}
-r \\
y
\end{array}\right)=\frac{(r+y-1)(r+y-2) \cdots(r)}{y !}=\frac{\Gamma(r+y)}{y ! \Gamma(r)}
$$


sehingga

$$
P(Y=y)=\left(\begin{array}{c}
r+y-1 \\
y
\end{array}\right)=\frac{\Gamma(r+y)}{y ! \Gamma(r)} p^{r}(1-p)^{y}
$$

Distribusi Binomial Negatif juga dibangkitkan dari sebaran Poisson dengan parameter $\lambda$ dan $\lambda$ juga merupakan sebuah peubah acak yang menyebar menurut distribusi Gamma $(r, p /(1-p))[7]$. Hal ini dapat dilihat pada penjabaran berikut

$$
\begin{aligned}
f(k) & =\int_{0}^{\infty} f_{\text {Poisson }(\lambda)}(k) f_{\text {Gamma }\left(r, \frac{p}{(1-p)}\right)}(\lambda) d \lambda, \\
& =\int_{0}^{\infty} \frac{\lambda^{k}}{k !} e^{-\lambda} \lambda^{r-1} \frac{e^{\frac{-\lambda(1-p)}{p}}}{\left(\frac{p}{1-p}\right)^{r} \Gamma(r)} d \lambda, \\
& =\frac{(1-p)^{r} p^{-r}}{k ! \Gamma(r)} \int_{0}^{\infty} \lambda^{r+k-1} e^{\frac{-\lambda}{p}} d \lambda, \\
& =\frac{(1-p)^{r} p^{-r}}{k ! \Gamma(r)} p^{r+k} \Gamma(r+k), \\
& =\frac{\Gamma(r+k)}{k ! \Gamma(r)}(1-p)^{r} p^{k} .
\end{aligned}
$$

\section{Karakterisasi Sebaran Binomial Negatif}

Jika $X$ merupakan peubah acak yang berdistribusi Binomial Negatif yang memiliki fungsi kepekatan peluang

$$
P(X=x)=\left(\begin{array}{c}
r+x-1 \\
x
\end{array}\right) p^{r}(1-p)^{x}
$$

dimana $x=0,1,2, \cdots$ dan $0 \leq p \leq 1$.

Nilai harapan dari peubah acak $X$ adalah

$$
E(X)=\frac{r(1-p)}{p} .
$$

Momen kedua dari peubah acak $X$ adalah

$$
E\left(X^{2}\right)=\frac{r(1-p)(1+r(1-p))}{p^{2}},
$$

sehingga nilai variansi dari peubah acak $X$ diperoleh

$$
\operatorname{Var}(X)=\frac{r(1-p)}{p^{2}}
$$

Adapun fungsi pembangkit momen dari peubah acak $X$, diperoleh dengan cara sebagai berikut

$$
M_{X}(t)=\left(\frac{p}{\left(1-(1-p) e^{t}\right)}\right)^{r}
$$


Dengan menggunakan fungsi pembangkit momen diperoleh nilai Skewness dari sebaran Binomial Negatif sebagai berikut.

$$
\begin{aligned}
\text { Skew }[X] & =\frac{E\left[(X-\mu)^{3}\right]}{\sigma^{3}} \\
& =\frac{p^{2}}{(q r)^{\frac{1}{2}}}\left[h_{1}-3 \frac{q r(1+q r)}{p^{2}}+2 \frac{q^{2} r^{2}}{p^{2}}\right]
\end{aligned}
$$

dimana

$$
h_{1}=(r-1)(r-2) \frac{q^{2}}{p^{2}}+3(r-1) \frac{q+2 p q^{2}}{p^{2}}+\frac{1+6 q}{p}+4 q+6 q^{2}
$$

dan nilai Kurtosis dari peubah acak sebaran Binomial Negatif adalah

$$
\operatorname{Kurt}[X]=\frac{p^{3}}{q r}\left[h_{2}-4 \frac{q r}{p} h_{1}+6 \frac{(q r)^{3}(1+q r)}{p^{2}}-3 \frac{(q r)^{3}}{p^{3}}\right] .
$$

dimana

$$
\begin{aligned}
h_{2}= & (r-1)(r-2)(r-3) \frac{q^{3}}{p^{3}}+6(r-1)(r-2) \frac{q^{2}}{p}(1+2 p q), \\
& \left.+4(r-1) \frac{q}{p}[1+6 q)+4 q+6 q^{2}\right]+\frac{1+15 q+42 q^{2}}{p}+8 q+12 q^{2}+24 q^{3} .
\end{aligned}
$$

\section{Fungsi Karakteristik Sebaran Binomial Negatif}

Fungsi Karakteristik merupakan fungsi yang selalu ada dimiliki oleh suatu peubah acak baik diskrit atau kontinu. Fungsi karakteristik dapat digunakan untuk membuktikan teorema-teorema yang penting dalam statistika, salah satunya adalah untuk membuktikan keterbagian tak hingga suatu sebaran. Pada Lukacs [5] terdapat beberapa sifat-sifat dari fungsi karakteristik sebagai berikut.

Proposisi 3.1. Misalkan $\varphi_{X}(t)$ merupakan fungsi karakteristik peubah acak $X$, $\operatorname{maka} \varphi_{X}(0)=1$.

Proposisi 3.2. Fungsi karakteristik ada untuk sebarang sebaran.

Proposisi 3.3. Misalkan $X$ suatu peubah acak dengan fungsi karakteristik $\varphi_{X}(t)$, maka fungsi karakteristik dari $-X$ adalah sekawan dari fungsi karakteristik $\varphi_{X}(t)$ atau dituliskan dengan $\overline{\varphi_{X}(t)}$.

Proposisi 3.4. Fungsi karakteristik $\varphi_{X}(t)$ adalah kontinu seragam.

Proposisi 3.5. Misalkan $X$ suatu peubah acak maka, fungsi karakteristik dari $a+$ $b X$ adalah $e^{i t a} \varphi_{X}(b t)$.

Fungsi karakteristik dari peubah acak $X$ yang berdistribusi Binomial Negatif dapat dirumuskan sebagai berikut

$$
\begin{aligned}
\varphi_{X}(t) & =E\left(e^{i t X}\right) \\
& =\sum_{x=0}^{\infty} e^{i t x}\left(\begin{array}{c}
r+x-1 \\
x
\end{array}\right) p^{r}(1-p)^{x} \\
& =p^{r} \sum_{x=0}^{\infty}\left(\begin{array}{c}
r+x-1 \\
x
\end{array}\right)\left((1-p) e^{i t}\right)^{x} .
\end{aligned}
$$


Misalkan $1-p^{*}=(1-p) e^{i t}$, maka

$$
\begin{aligned}
& =p^{r} \sum_{x=0}^{\infty}\left(\begin{array}{c}
r+x-1 \\
x
\end{array}\right)\left(1-p^{*}\right)^{x} \frac{\left(p^{*}\right)^{r}}{\left(p^{*}\right)^{r}}, \\
& =\frac{p^{r}}{\left(p^{*}\right)^{r}} \sum_{x=0}^{\infty}\left(\begin{array}{c}
r+x-1 \\
x
\end{array}\right)\left(1-p^{*}\right)^{x}\left(p^{*}\right)^{r}, \\
& =\frac{p^{r}}{\left(1(1-p) e^{i t}\right)^{r}}, \\
& =\left(\frac{p}{\left(1-(1-p) e^{i t}\right)}\right)^{r} .
\end{aligned}
$$

Akan ditunjukkan fungsi karakteristik $\varphi_{X}(t)$ memenuhi sifat-sifat fungsi karakteristik berikut.

Sifat 3.6. Misalkan $\varphi_{X}(t)=\left(\frac{p}{\left(1-(1-p) e^{i t}\right)}\right)^{r} \operatorname{maka} \varphi_{X}(0)=1$.

Penjelasan. Perhatikan bahwa

$$
\begin{aligned}
\varphi_{X}(t) & =\left(\frac{p}{\left(1-(1-p) e^{i t}\right)}\right)^{r} \\
\varphi_{X}(0) & =\left(\frac{p}{\left(1-(1-p) e^{0}\right)}\right)^{r}, \\
& =\left(\frac{p}{p}\right)^{r}, \\
& =1 .
\end{aligned}
$$

Sifat 3.7. Misalkan $X$ suatu peubah acak dengan fungsi karakteristik $\varphi_{X}(t)$, maka fungsi karakteristik dari $-X$ adalah sekawan dari fungsi karakteristik $\varphi_{X}(t)$ atau dituliskan dengan $\overline{\varphi_{X}(t)}$.

Penjelasan. Fungsi karakteristik peubah acak $-X$ adalah

$$
\begin{aligned}
\varphi_{-X}(t) & =E\left(e^{-i t X}\right) \\
& =\sum_{x=0}^{\infty} e^{-i t x}\left(\begin{array}{c}
r+x-1 \\
x
\end{array}\right) p^{r}(1-p)^{x}, \\
& =p^{r} \sum_{x=0}^{\infty}\left(\begin{array}{c}
r+x-1 \\
x
\end{array}\right)\left((1-p) e^{-i t}\right)^{x} .
\end{aligned}
$$

Misalkan $1-p^{*}=(1-p) e^{-i t}$, maka

$$
\begin{aligned}
& =p^{r} \sum_{x=0}^{\infty}\left(\begin{array}{c}
r+x-1 \\
x
\end{array}\right)\left(1-p^{*}\right)^{x} \frac{\left(p^{*}\right)^{r}}{\left(p^{*}\right)^{r}}, \\
& =\frac{p^{r}}{\left(p^{*}\right)^{r}} \sum_{x=0}^{\infty}\left(\begin{array}{c}
r+x-1 \\
x
\end{array}\right)\left(1-p^{*}\right)^{x}\left(p^{*}\right)^{r}, \\
& =\frac{p^{r}}{\left(1(1-p) e^{-i t}\right)^{r}}, \\
& =\left(\frac{p}{\left(1-(1-p) e^{-i t}\right)}\right)^{r} .
\end{aligned}
$$


Sifat 3.8. Fungsi karakteristik $\varphi_{X}(t)=\left(\frac{p}{\left(1-(1-p) e^{i t}\right)}\right)^{r}$ adalah kontinu seragam.

Penjelasan. Misalkan $\varphi_{X}(t)=\left(\frac{p}{\left(1-(1-p) e^{i t}\right)}\right)^{r}$ dan $h=s-t$ dimana $s>t$, maka akan ditunjukkan setiap $\epsilon>0$ terdapat $\delta>0$ sedemikian sehingga $\left|\varphi_{X}(s)-\varphi_{X}(t)\right|<$ $\epsilon$ untuk $|s-t|<\delta$. Perhatikan bahwa

$$
\begin{aligned}
\left|\varphi_{X}(s)-\varphi_{X}(t)\right| & =\left|\left(\frac{1}{1-(1-p) e^{i s}}\right)^{r}-\left(\frac{1}{1-(1-p) e^{i s t}}\right)^{r}\right|, \\
& =\left|\left(\sum_{m=0}^{\infty}(1-p) e^{i s}\right)^{m r}-\left(\sum_{m=0}^{\infty}(1-p) e^{i t}\right)^{m r}\right|, \\
& =\left|\left(\sum_{m=0}^{\infty}(1-p) e^{i(h+t)}\right)^{m r}-\left(\sum_{m=0}^{\infty}(1-p) e^{i t}\right)^{m r}\right| .
\end{aligned}
$$

Untuk $h \rightarrow 0$ maka $\left|\varphi_{X}(s)-\varphi_{X}(t)\right| \rightarrow 0$ dimana $|s-t| \rightarrow 0$. Hal ini menunjukkan $\delta$ bergantung pada $\epsilon$ dimana $\left|\varphi_{X}(s)-\varphi_{X}(t)\right|<\epsilon$ untuk $|s-t|<\delta$.

Sifat 3.9. Misalkan $X$ suatu peubah acak, maka fungsi karakteristik dari $a+b X$ adalah $e^{i t a} \varphi_{X}(b t)$.

Penjelasan. Perhatikan bahwa

$$
\begin{aligned}
\varphi_{a+b X}(t) & =E\left(e^{i t(a+b X)}\right) \\
& =\sum_{x=0}^{\infty} e^{i t a} e^{i t b x}\left(\begin{array}{c}
r+x-1 \\
x
\end{array}\right) p^{r}(1-p)^{x}, \\
& =e^{i t a} p^{r} \sum_{x=0}^{\infty}\left(\begin{array}{c}
r+x-1 \\
x
\end{array}\right)\left((1-p) e^{i t b}\right)^{x} .
\end{aligned}
$$

Misalkan $1-p^{*}=(1-p) e^{i t b}$, maka

$$
\begin{aligned}
& =e^{i t a} p^{r} \sum_{x=0}^{\infty}\left(\begin{array}{c}
r+x-1 \\
x
\end{array}\right)\left(1-p^{*}\right)^{x} \frac{\left(p^{*}\right)^{r}}{\left(p^{*}\right)^{r}} \\
& =e^{i t a} \frac{p^{r}}{\left(p^{*}\right)^{r}} \sum_{x=0}^{\infty}\left(\begin{array}{c}
r+x-1 \\
x
\end{array}\right)\left(1-p^{*}\right)^{x}\left(p^{*}\right)^{r} \\
& =e^{i t a} \frac{p^{r}}{\left(1(1-p) e^{i t b}\right)^{r}}, \\
& =e^{i t a}\left(\frac{p}{\left(1-(1-p) e^{i t b}\right)}\right)^{r} \\
& =e^{i t a} \varphi_{X}(b t)
\end{aligned}
$$

\section{Daftar Pustaka}

[1] Bain, L.J. dan M. Engelhardt. 1992. Introduction to Probability and Mathematical Statistics Second Edition. Duxbury Press, California.

[2] Casella, G. dan R. L, Berger. 1990.Statistical Inference. Ed. Ke-1, Pasific Grove, California. 
70 Deby Handayani dkk.

[3] Chung, K. L. 2001. A Course In Probability Theory. $3^{\text {rd }}$ ed. San Diego: Academy Press.

[4] Laha, R.G dan V.K, Rohagi. 1979. Probability Theory. New York: John Wiley Son.

[5] Lukacs, E. 1992. Characteristic Function. $2^{\text {nd }}$ ed. london: Griffin.

[6] Panjer, H. H. dan G. E. Willot. 1981. Finite Sum Evaluation of The Negative Binomial-Eksponensial Model. Astin Bulletin. 133-137.

[7] Paul, D. I. 2013. A Critical Review of Some Properties and Applications of The Negative Binomial Distribution and Its Relation to Other Probability Distribution. International Buletin Journal of Engineering and Science 2 : $33-34$.

[8] Tucker, H. G. 1967. Probability and Mathematical Statistics. London: Academy Press.

[9] Wang, Z. 2011. One Mix Negative Binomial Distribution with Application. Statistical Planning 141 : 1153 - 1160. 